nhóm người bênh có đáp ứng. Với độc tính và tác dụng phụ của thuốc khá thường gặp.

\section{TÀI LIẸU THAM KHẢO}

1. Lai Thị Thanh Thảo, Huỳnh Hồng Hoa. (2015), "Báo cáo các trường hợp rối loạn sinh tủy được điêuu trị bằng Decitabine tại bệnh viện Chợ Rấy", Y hoc thành phố Hồ Chí Minh, (1), pp. tr.1.

2. Huỳnh Thi Bích Huyên, Lê Phương Thảo, Nguyễn Hữu Nhân, et al, Chẩn đoán, phân loai và tiên lượng loạn sinh tùy theo WHO 2016 tai bệnh viện Truyền máu Huyết học thành phố Hồ Chí Minh, 2019: Sở y tế, bệnh viện Truyên máu Huyết học. pp. tr34.

3. Nguyễn Quang Hảo, Trân Tuấn Anh, Lưu Thi Thu Hương. (2021), "Kết quả điều trị loạn sinh tủy bằng decitabine tại viện Huyết hoc - Truyền máu Trung ương", Tap chí nghiên cứu y hoc, pp. tr.1-9.

4. Cheson Bruce $D$, Greenberg Peter $L$, Bennett John $\mathbf{M}$, et al. (2006), "Clinical application and proposal for modification of the International Working Group (IWG) response criteria in myelodysplasia", Blood, 108 (2), pp. pp.419-425.
5. Kenneth Kaushansky Marshall A. Lichtman, et al,. (2016), "Myelodysplastic syndromes", Williams Hematology, 9th, Mc Graw Hill, New York Chicago San Francisco Athens London Madrid Mexico City Milan New Delhi Singapore Sydney Toronto, pp. pp.1341.

6. NCCN. (version 3.2021), "Myelodysplastic Syndromes".

7. Kantarjian Hagop, Issa Jean-Pierre J, Rosenfeld Craig S, et al. (2006), "Decitabine improves patient outcomes in myelodysplastic syndromes: results of a phase III randomized study", Cancer: Interdisciplinary International Journal of the American Cancer Society, 106 (8), pp. 1794-1803.

8. Saba Hussain, Rosenfeld Craig, Issa JeanPierre, et al, First report of the phase III North American trial of decitabine in advanced myelodysplastic syndrome (MDS), 2004, American Society of Hematology.

9. Steensma David P. (2018), "Myelodysplastic syndromes current treatment algorithm 2018", Blood cancer journal, 8 (5), pp. 1-7.

\title{
ĐĂC ĐIỂM DİCH TỄ, LÂM SÀNG CỦA BÊNNH THIẾU VITAMIN D Ở TRẺ EM DƯớI 5 TUỔI TẠI TRƯờNG THỌ, AN LÃO, HẢI PHÒNG, NĂM 2017
}

\section{TÓM TẮT}

Muc tiêu: Xác đinh tỷ lê thiếu vitamin D ở trẻ dưới 5 tuổi tại Trường Thọ, An Lã்o năm 2017 và mô tả 1 số triêu chứng lâm sàng của bênh còi xương ở đối tượng nghiên cứu. Đối tượng: là trẻ em $\leq 60$ tháng sinh ra và có hô khẩu thường trú tai xã Trường Tho huyên An Lão. Phương pháp: Nghiển cứu mô tả cắt ngang và hồi cứu. Kết quả và kết luân: Tỷ lê trẻ trai là 54,8\% cao hơn trẻ gái là $45,2 \%$, tỷ lệ trai/gái là 1,2. Lứa tuổi từ 24- 60 tháng chiếm tỳ lệ cao nhất 75,44\%. Tỷ lệ thiếu/hụt Vitamin D ở trẻ là 93,86\%, trong đó trẻ trai là $54,21 \%$ cao hơn trẻ gái là $45,79 \%$. Tỷ lệ trẻ thiếu/hụt Vitamin D cao nhất là ở lứa tuổi từ 24- 60 tháng $(76,17 \%)$. Trong nghiên cứu của chúng tôi, khi khám sàng lọc dựa vào các triệu chứng lâm sàng đã phát hiện 123 trẻ có biểu hiện quấy khóc $(53,95 \%)$ trẻ có dấu hiệu ngủ không yên giấc, giật mình là 124 trẻ $(54,39 \%)$, trẻ có dấu hiệu vã mô hồi, rụng tóc là 124 trẻ $(54,39 \%)$.

Tư khóa: Thiếu vitamin D, hụt vitamin D, còi xương.

\section{SUMMARY \\ THE INCINDENCE, SYMTOM OF VITAMIN D}

*Bệnh viện Trẻ em Hải Phòng

**Trường Đai hoc Y Dược Hải Phòng

Chịu trách nhiệm chính: Nguyễn Thị Ngọc Yến

Email: bsyenbvte@gmail.com

Ngày nhận bài: 3.6.2021

Ngày phản biên khoa hoc: 2.8.2021

Ngày duyệt bài: 9.8.2021

\section{DEFICIENCY IN CHILDREN UNDER 5 IN} TRUONG THO, AN LAO, HAI PHONG IN 2017

Objectives: estimate the prevelence of vitamin $D$ deficiency in children under 5 at Truong Tho, An Lao, in 2017and describe some clinical signs of ricket in these participants. Population: included 228 children under 5 who were born in Truong Tho, An Lao. Method: It was a cross sectional study. Results and Conclusions: More males $(54.8 \%)$ than females $(45.2 \%)$ paticipated in the study, male/female ratio was 1.2. 24- 60 group represented the highest rate $75.44 \%$. The prevalence of Vitamin D insufficiency and deficiency were $93.86 \%$ and among them, $54.21 \%$ males and $45.79 \%$ females. The Vitamin D insufficiency and deficiency was the highest in 24- 60 months group (76.17\%). There were 123 children with crying (53.95\%), not well sleeping, startle (54.39\%), sweating and hair loss (54.39\%).

Keywords. Insufficiency, Deficiency, ricket.

\section{I. ĐăT VẤN ĐỀ}

Từ thế kỷ 19 vitamin $D$ được biết đến như là một hoạt chất có ảnh hưởng đến sự phát triển và duy trì xương. Các phát hiện này cũng đã chỉ ra thiếu hụt vitamin $D$ không chỉ làm tăng nguy cơ mắc bệnh loãng xương, tim mạch, cao huyết áp, đái tháo đường, vẩy nến, viêm đường ruột, viêm khớp, viêm gan, nhiễm trùng, lao phổi, v.v... mà còn tăng nguy cơ mắc bệnh ung thư'. Người thiếu vitamin $D$ thường hay bị đau nhức 
cơ bắp, hay bị té ngã và dễ bị gãy xương [4]. Trẻ em thiếu vitamin $D$ sẽ gây bệnh còi xương, khả năng miễn dịch kém và dễ bị viêm đường hô hấp.

Thiếu vitamin $D$ là bệnh phổ biến ở các nước đang phát triển, tỷ lệ mắc bệnh tùy từng vùng Iãnh thổ, thay đổi từ $30-90 \%$. Trung Quốc và Mông Cổ là hai quốc gia có tỷ lệ bệnh cao (50\%). Theo số liệu của Peterlik $M$ và cộng sự [7] xem xét từ 46 nghiên cứu ở châu Âu, Bắc Mỹ, Đông Nam Á và Nam Thái Bình Dương thấy rằng 30-80\% dân số có nồng đô vitamin $D$ thấp.

Ơ nước ta, còn ít nghiên cứu đánh giá về tình trạng thiếu vitamin $D$ của trẻ em trong cộng đồng và những biện pháp can thiệp triệt để trong phòng chống thiếu vitamin $D$. Kết quả một số công trình nghiên cứu cho thấy tỉ lệ thiếu vitamin $\mathrm{D}$ trong cộng đồng còn khá cao. Vì vậy, chúng tôi tiến hành nghiên cứu này với mục tiều

1. Xác định tỷ lệ thiêu vitamin $D$ ở trẻ dưới 5 tuổi tại Trường Thọ, An Lão nămm 2017

2. Mô tả 1 số triệu chứng lâm sàng của bệnh còi xương ở đối tượing nghiên cứu

\section{II. ĐỐI TƯỢNG VÀ PHƯƠNG PHÁP NGHIÊN CỨU}

- Đối tượng nghiên cứu: là trẻ em $\leq 5$ tuổi, được sinh ra và có hộ khẩu thường trú tại xã Trường Thọ huyện An Lão, được bố mẹ đồng ý tham gia vào nghiên cứu và đủ các tiêu chuẩn lựa chon.

- Thiết kế nghiên cứu: Nghiên cứu mô tả cắt ngang

*Chẩn đoán sàng lọc trẻ thiếu vitamin D:

- Lâm sàng

. Triệu chứng toàn thân: cân nặng, chiều cao, hạch ngoại vi, tuyên giáp, da và niêm mạc, lông tóc móng, tổ chức dưới da, ra mồ hôi trộm, ngủ không yên giấc (hay giật ình, quây khóc ban đêm, rụng tóc sau gáy)

- Triệu chứng ở xương: xương đầu (hình dạng, kích thước, kích thước thóp trước), xương lồng ngực (chuỗi hạt sườn, ngực gà, ngự hình chuông), xương chi (vòng cổ tay, vòng cổ chân), xương cột sống (gù veo cột sống).

. Triệu chứng ở hể cơ và dây chằng: trương lực cơ và cơ lực.

- Cận lâm sàng: Định lượng vitamin $D$ trong máu bằng xét nghiệm miễn dịch điện hóa quang.

\begin{tabular}{|c|c|}
\hline $\begin{array}{c}\text { Hàm lượng 25 } \mathbf{( O H}) \\
\text { D huyêt thanh }\end{array}$ & $\begin{array}{c}\text { Tình tranng } \\
\text { vitamin D }\end{array}$ \\
\hline$>30 \mathrm{ng} / \mathrm{mL}$ & Đủ vitamin D \\
\hline $20-30 \mathrm{ng} / \mathrm{mL}$ & Hụt vitamin D \\
\hline$<20 \mathrm{ng} / \mathrm{mL}$ & Thiếu vitamin $\mathrm{D}$ \\
\hline
\end{tabular}

- Xử lý số liệu theo phương pháp thống kê Y học

\section{KẾT QUẢ NGHIÊN CỨU}

3.1. Tỷ lê thiếu vitamin $D$ ở trẻ dưới 5 tuổi tại Trường Thọ, An Lão năm 2017

3.1.1. Thông tin về đôî tương nghiên cứu

Bảng 3.1. Phân bố đối tượng nghiên cứu theo giới

\begin{tabular}{|c|c|c|c|}
\hline Giới & $\begin{array}{c}\text { Số trẻ điều } \\
\text { tra (n) }\end{array}$ & $\begin{array}{c}\text { Số lượng } \\
\text { (n) }\end{array}$ & $\begin{array}{c}\text { Tỷ lệ } \\
\text { (\%) }\end{array}$ \\
\hline Trai & 420 & 125 & 29,76 \\
\hline Gái & 378 & 103 & 27,25 \\
\hline Tống số & $\mathbf{7 9 8}$ & $\mathbf{2 2 8}$ & $\mathbf{2 8 , 5 7}$ \\
\hline
\end{tabular}

Nhận xét: Nhóm nghiên của chúng tôi có 125 trẻ trai $(29,76 \%)$ và có 103 trẻ gái $(27,25 \%)$

Bảng 3.2. Phân bố đôi tượng nghiên cứu theo lứa tuôi

\begin{tabular}{|c|c|c|c|}
\hline Tuổi & $\begin{array}{c}\text { Số trẻ điều } \\
\text { tra(n) }\end{array}$ & $\begin{array}{c}\text { Số } \\
\text { ượng(n) }\end{array}$ & $\begin{array}{c}\text { Tỷ lệ } \\
\mathbf{( \% )}\end{array}$ \\
\hline$<6$ tháng & 66 & 1 & 1,52 \\
\hline $6-12$ tháng & 75 & 5 & 6,67 \\
\hline $12-<18$ tháng & 51 & 22 & 43,14 \\
\hline $18-<24$ tháng & 27 & 27 & 100 \\
\hline 24 tháng-5tuối & 579 & 173 & 29,88 \\
\hline Tống số & $\mathbf{7 9 8}$ & $\mathbf{2 2 8}$ & $\mathbf{2 8 , 5 7}$ \\
\hline Nhấn xét: Lứa tuối có biếu hiện thiếu
\end{tabular}

Vitamin D cao nhất là 18-24 tháng tuổi $(100 \%)$, lứa tuổi từ 12-dưới 18 tháng gặp 43,14\%

\subsubsection{Tỷ lệ thiếu vitamin $D$}

Bảng 3.3. Tỷ lế thiếu vitamin D

\begin{tabular}{|c|c|c|c|c|}
\hline $\begin{array}{l}\text { Tỳ lệ thiếu hụt } \\
\text { vitamin D }\end{array}$ & Số l & $\begin{array}{l}\text { iơong } \\
\text { i) }\end{array}$ & Tỷ lé & (\%) \\
\hline $\begin{array}{c}\text { Bình thường( } \\
\text { 30ng/mL) }\end{array}$ & \multirow{3}{*}{\multicolumn{2}{|c|}{\begin{tabular}{|c|} 
(n) \\
14
\end{tabular}}} & \multicolumn{2}{|c|}{6.14} \\
\hline $\begin{array}{l}\text { Hụt }(20-30 \\
\mathrm{ng} / \mathrm{mL})\end{array}$ & & & 57.02 & \\
\hline $\begin{array}{c}\text { Thiếu(< } 20 \\
\mathrm{ng} / \mathrm{mL})\end{array}$ & & & 36.84 & 93.86 \\
\hline
\end{tabular}

Nhận xét: Số trẻ trong nhóm nghiên cứu có tỷ lệ thiếu/hut Vitamin $D$ chiếm tỷ lệ cao $93,86 \%$. Chỉ có $6,17 \%$ trẻ có định lượng Vitamin D ở mức bình thường.

Bảng 3.4. Tý lệ thiêu hụt vitamin D theo giới

\begin{tabular}{|c|c|c|}
\hline Giới & Số lượng (n) & Tỷ lệ (\%) \\
\hline Trai & 116 & 54,21 \\
\hline Gái & 98 & 45,79 \\
\hline Tống số & $\mathbf{2 1 4}$ & $\mathbf{1 0 0}$ \\
\hline
\end{tabular}

Nhân xét: Tỷ lê thiếu/ hut Vitamin $\mathrm{D}$ ở trẻ trai cao hơn trẻ gái $(54,21 \%$ và $45,79 \%)$

Bảng 3.5. Tỷ lệ thiếu/ hụt vitamin D theo tuôi

\begin{tabular}{|c|c|c|}
\hline Tuổi & $\begin{array}{c}\text { Số trẻ } \\
\text { thiếu/hụt } \\
\text { vitamin } \mathbf{D ( n )}\end{array}$ & $\begin{array}{c}\text { Tỷ lệ } \\
\mathbf{( \% )}\end{array}$ \\
\hline <6 tháng & 1 & 0,47 \\
\hline 6 tháng-12 tháng & 5 & 2,34 \\
\hline
\end{tabular}




\begin{tabular}{|c|c|c|}
\hline $12-<18$ tháng & 21 & 9,81 \\
\hline $18-<24$ tháng & 24 & 11,21 \\
\hline 24 tháng -5 tuối & 163 & 76,17 \\
\hline Tống số & $\mathbf{2 1 4}$ & $\mathbf{1 0 0}$ \\
\hline
\end{tabular}

Nhân xét: Trẻ thiếu/hụt Vitamin D gặp cao nhất ở nhóm tuổi $24-60$ tháng $(76,17 \%)$. Nhóm tuổi từ 6 tháng đến 24 tháng chỉ gặp từ Tổng số 214 2,34\% đến $11,21 \%$.

3.2. Triệu chứng lâm sàng của bệnh còi xương ở đối tượng nghiên cứu

Bảng 3.6: Triệu chứng lâm sàng toàn thân biểu hiện thiếu vitamin $D$ ở đối tượng nghiên cứu

\begin{tabular}{|c|c|c|c|c|}
\hline Biểu hiện thiếu/hụt vitamin & \multicolumn{2}{|c|}{ Không có triệu chứng } & \multicolumn{2}{c|}{ Có triệu chứng } \\
\cline { 2 - 5 } D & Số lượng (n) & Tỷ lệ (\%) & Số lượng (n) & Tỳ lệ (\%) \\
\hline Da niêm mạc hồng & 0 & 0 & 214 & 100 \\
\hline Quấy khóc & 124 & 57,94 & 90 & 42,06 \\
\hline Ngủ không yên giấc, giật mình & 124 & 57,94 & 90 & 42,06 \\
\hline Ra mồ hôi trộm & 124 & 57,94 & 90 & 42,06 \\
\hline Rụng tóc sau gáy & 124 & 57,94 & 90 & 42,06 \\
\hline
\end{tabular}

Nhân xét: Tỷ lệ trẻ có biếu hiện quấy khóc $(57,94 \%)$, trẻ có dấu hiệu ngủ không yên giấc, giật mình lầ 124 trẻ $(57,94 \%)$, trẻ có dẩu hiệu vã mồ hôi, rụng tóc là 124 trẻ $(57,94 \%)$.

Bảng 3.7: Triệu chứng lâm sàng ở hệ xương biểu hiện thiêu vitamin $D$ ở đôî tượng nghiên cứu

\begin{tabular}{|c|c|c|c|c|c|}
\hline \multirow[b]{2}{*}{ Cơ quan } & \multirow[b]{2}{*}{$\begin{array}{c}\text { Biểu hiện thiếu/hụt } \\
\text { vitamin D }\end{array}$} & \multicolumn{2}{|c|}{ Không có triệu chứng } & \multicolumn{2}{|c|}{ Có triệu chứng } \\
\hline & & $\begin{array}{l}\text { Số lượng } \\
\text { (n) }\end{array}$ & $\begin{array}{l}\text { Tỷ lệ } \\
(\%)\end{array}$ & $\begin{array}{l}\text { Số lượng } \\
\text { (n) }\end{array}$ & $\begin{array}{l}\text { Tỷ lệ } \\
(\%)\end{array}$ \\
\hline \multirow{6}{*}{ Xương sọ } & Mềm xương sọ & 214 & 93.86 & 0 & 0 \\
\hline & Thóp rộng & 180 & 78,9 & 34 & 14,9 \\
\hline & Bờ thóp mềm & 180 & 78,9 & 34 & 14,9 \\
\hline & Có bướu trán & 214 & 93.86 & 0 & 0 \\
\hline & Biến dạng xương hàm & 214 & 93.86 & 0 & 0 \\
\hline & Răng moc lộn xộn & 214 & 93.86 & 0 & 0 \\
\hline \multirow{4}{*}{$\begin{array}{l}\text { Xương lồng } \\
\text { ngực }\end{array}$} & Lông ngực biến dạng & 214 & 93.86 & 0 & 0 \\
\hline & Chuối hat sườn & 214 & 93.86 & 0 & 0 \\
\hline & Ngực gà & 214 & 93.86 & 0 & 0 \\
\hline & Ngức hình chuông & 214 & 93.86 & 0 & 0 \\
\hline \multirow{3}{*}{ Xương chi } & Vòng cố tay & 214 & 93.86 & 0 & 0 \\
\hline & Vòng cố chân & 214 & 93.86 & 0 & 0 \\
\hline & Chân vòng kiềng & 189 & 82,9 & 25 & 10,9 \\
\hline \multirow{2}{*}{ Xương cột sống } & Gù vẹo cột sống & 214 & 93.86 & 0 & 0 \\
\hline & Xương chậu hẹp & 214 & 93.86 & 0 & 0 \\
\hline \multirow{2}{*}{$\begin{array}{l}\text { Hệ cơ và dây } \\
\text { chằng }\end{array}$} & Trương lực cơ giảm & 214 & 93.86 & 0 & 0 \\
\hline & Teo co & 214 & 93.86 & 0 & 0 \\
\hline
\end{tabular}

Nhận xét: Trong 228 trẻ nghiên cứu của chúng tôi có 214 trẻ có biểu hiện thiếu/hụt Vitamin $D$ tuy nhiên $100 \%$ số trẻ này đều không có các biểu hiện muộn của còi xương thiếu Vitamin $D$ như mềm xương sọ, có bướu trán, biến dạng xương hàm, răng mọc lộn xộn... Chỉ có $14,9 \%$ trẻ có biểu hiện thóp rộng và bờ thóp mềm, có 25 trẻ có biểu hiện chân vòng kiềng chiếm tỷ lệ $10,9 \%$.

\section{BÀN LUẬN}

Nghiên cứu của chúng tôi đã thực hiện với 228 trẻ xã Trường Thọ, Huyện An Lão, Hải phòng. Trong số nhóm trẻ nghiên cứu, số trẻ nam là 125 chiếm $55,1 \%$, trẻ nữ là 103 chiếm $44,9 \%$. Số trẻ ở độ tuổi $18-24$ tháng là 28 trẻ chiếm $12,8 \%$, trẻ từ $24-60$ tháng là 172 trẻ chiếm 75,44\% (bảng 3.1).

Trong nghiên cứu này, chúng tôi sử dụng ngưỡng chẩn đoán thiếu vitamin $\mathrm{D}$ khi hàm lượng $25(\mathrm{OH}) \mathrm{D}<20 \mathrm{ng} / \mathrm{ml}$, và hàm lượng vitamin
D huyết thanh thấp khi $25(\mathrm{OH}) \mathrm{D}$ trong huyết thanh $>20 \mathrm{ng} / \mathrm{ml}$ và $<30 \mathrm{ng} / \mathrm{ml}$, đây là ngưỡng mà đa số tác giả trên thế giới hiện nay thửa nhận. Kết quả ở bảng 3.3 cho thấy tỷ lệ thiếu vitamin $\mathrm{D}$ ở trẻ trong nhóm nghiên cứu là 214 trẻ chiếm tỷ lệ $93,86 \%$, trong đó trẻ có lượng Vitamin từ $20-30 \mathrm{ng} / \mathrm{ml}$ chiếm tỷ lệ $57,02 \%$, tỷ lệ trẻ có hàm lượng viatmin $D$ huyết thanh dưới $20 \mathrm{ng} / \mathrm{ml}$ là $36,84 \%$.

Với cùng ngưỡng chẩn đoán, thì tỷ lệ thiếu vitamin D ở trẻ em Quatar 0- 5 tuổi là 19,5\% 
thấp hơn kết quả của chúng tôi [5]. Tác giả Jonathal nghiên cứu tình trạng vitamin $D$ huyết thanh ở trẻ em từ 1 đến 11 tuổi ở Mỹ cho thấy trẻ từ 1- 5 tuổi có hàm lượng vitamin $D$ thấp chiếm $63 \%$, tỷ lệ này cao hơn nghiên cứu của chúng tôi. Trẻ em trong độ tuổi từ 1- 5 năm có nồng độ vitamin $D$ huyết thanh trung bình là $70 \mathrm{nmol} / \mathrm{l}$. Kết quả của tác giả cho thấy nồng độ vitamin $D$ huyết thanh trung bình thấp dần ở nhóm tuổi lớn hơn và tỷ lệ thiếu vitamin $\mathrm{D}$ cũng tăng dần theo tuổi [8].

Kết quả bảng 3.5 cho thấy, trong số 214 trẻ thiếu/hụt Vitamin $D$, trẻ có lứa tuổi từ 24- 60 tháng là 163 trẻ chiếm tỷ lệ $76,17 \%$, trẻ từ 1824 tháng là 24 trẻ chiếm tỷ lệ $11,21 \%$, số trẻ dưới 6 tháng chếm tỷ lệ thấp nhất $0,47 \%$, lứa tuổi từ 6 đến dưới 18 tháng chỉ chiếm từ 2,34\% đến $9,81 \%$. Nghiên cứu ở Trung Quốc cho thây tỷ lệ thiếu vitamin $D$ ở trẻ từ 12 đến 24 tháng là $65,3 \%$, cao hơn kết quả trong bảng 3.5. Như vậy, tỷ lệ thiếu vitamin $D$ ở đối tượng nghiên cứu cao hơn trẻ cùng độ tuổi ở Quatari [5], thấp hơn so với trẻ ở Mỹ [8]và Trung Quốc [9]

Bảng 3.5 cho thấy tỷ lệ thiếu/hụt vitamin $D$ huyết thanh ở nhóm trẻ 12- dưới 18 tháng là 9,81\%, nhóm trẻ 18- dưới 24 tháng là 11,24\%. Không có sự khác biệt về tỷ lệ thiếu vitamin $D$ giữa hai nhóm tuổi, $p>0,05$. Trong kết quả bảng 3.4 , tỷ lệ thiếu vitamin $\mathrm{D}$ của trẻ trai cao hơn trẻ gái $(54,21 \%$ và $45,79 \%)$, nhưng sự khác biệt này không có ý nghĩa thống kê, $\mathrm{p}>0,05$. Nhóm trẻ trai có nguy cơ bị thiếu vitamin $D$ huyết thanh cao hơn nhóm trẻ gái. So với những nghiên cứu trước của tác giả Vũ Thị Thu Hiền và cộng sự thì tỷ lệ thiếu vitamin $D$ ở trẻ 12-36 tháng (49\%) cao hơn trẻ 1-6 tháng trong kết quả của tác giả $(23,6 \%)[1]$. Kết quả về tỷ lệ thiếu vitamin $\mathrm{D}$ này của chúng tôi tương đương với trẻ 6- 11 tuổi (48\%-53\%) trong kết quả nghiên cứu của tác giả Lê Nguyến Bảo Khanh.

So sánh với kết quả nghiên cứu tại Việt Nam năm 2013 ở trẻ em từ 6 tháng đến 6 tuổi của 19 tỉnh trên toàn quốc thì thấy có sự tương đương về tỷ lệ trẻ có nồng độ vitamin $\mathrm{D}<20 \mathrm{ng} / \mathrm{ml}$ là $50 \%$ [3], kết quả của chúng tôi là $36,84 \%$, nhưng lại khác nhau về tỷ lệ trẻ có nồng độ vitamin $\dot{D}<30 \mathrm{mg} / \mathrm{ml}$ là $89,0 \%$ cao hơn nghiên cứu của chúng tôi $(57,02 \%)$. Theo các tài liệu cho thấy, nghiên cứu này là một trong các dữ liệu báo cáo đầu tiên về tình trạng vitamin $\mathrm{D}$ ở trẻ em tại Việt Nam. Hơn nữa, rất ít dữ liệu về tình trạng thiểu hụt vitamin $D$ ở trẻ em ở châu Á đã được báo cáo [3].

Thiếu vitamin $D$ là nguyên nhân chính gây bệnh còi xương dinh dưỡng ở trẻ nhỏ. Triệu chứng lâm sàng của bệnh còi xương cấp bao gồm trẻ hay bị kích thích thần kinh, ra mồ hôi trộm, ở trẻ nhỏ có thóp rộng, liền chậm, răng mọc chậm, tóc rụng, điển hình là tóc rựng hình vành khăn... Nếu không được điều trị, trẻ bị còi xương kéo dài dẫn đến biến dạng chi, chân hình chữ $X, Y$. Đầu có bướu, xương sườn biến dạng, có rãnh sườn, chuối hạt sườn, vòng cổ tay, cổ chân...Hậu quả lâu dài sẽ làm trẻ chậm tăng trưởng chiều cao. Các dấu hiệu cận lâm sàng có phosphatase kiềm tăng, hình ảnh $X$ quang có cốt hóa đầu xương chậm, biến dạng xương. Trong nghiên cứu của chúng tôi, khi khám sàng lọc dựa vào các triệu chứng lâm sàng đã phát hiện 123 trẻ có biểu hiện quấy khóc $(53,95 \%)$, trẻ có dấu hiệu ngủ không yên giấc, giật mình là 124 trẻ $(54,39 \%)$, trẻ có dấu hiệu vã mồ hôi, rụng tóc là 124 trẻ $(54,39 \%)$. Trong 228 trẻ nghiên cứu của chúng tôi có 214 trẻ có biểu hiện thiếu/hụt Vitamin $D$ tuy nhiên $100 \%$ số trẻ này đều không có các biểu hiện muộn của còi xương thiếu Vitamin $D$ như mềm xương sọ, có bướu trán, biến dạng xương hàm, răng mọc lộn xộn... Chỉ có $14,9 \%$ trẻ có biểu hiện thóp rộng và bờ thóp mềm, có 25 trẻ có biểu hiện chân vòng kiềng chiếm tỷ lệ 10,9\%.

Trong nghiên cứu tại Trung Quốc có kết quả bệnh còi xương chẩn đoán chỉ dựa vào dấu hiệu lâm sàng đã xác định tỷ lệ còi xương là $41,6 \%$ vào mùa xuân. Qua thời gian mùa hè, tỷ lệ này đã giảm xuống còn $17,0 \%$ vào mùa thu, sự khác biệt có ý nghĩa thống kê với $p=0,004$. Nghiên cứu cho thấy nếu chẩn đoán dựa vào các dấu hiệu lâm sàng, hình ảnh Xquang và cả phosphatase kiềm thì tỷ lệ của bệnh còi xương đang hoạt động là $3,7 \%$. Tỷ lệ này thấp hơn nghiên cứu của tác giả Nguyến Văn Sơn nghiên cứu về các yếu tố nguy cơ còi xương dinh dưỡng ở trẻ em dưới 3 tuổi tại một số vùng miền núi phía Bắc và hiệu quả điều trị bằng vitamin $D$ liều thấp cho thấy tỳ lệ còi xương chung khoảng $14,4 \%$. Tỷ lệ còi xương tuổi $13-18$ tháng là $18,5 \%, 19-24$ tháng là $12,4 \%, 25-36$ tháng là $7,6 \%$. Tỷ lệ còi xương theo tác giả thấp dần ở các nhóm tuổi cao hơn [2].

\section{KẾT LUẬN}

\section{Xác định tỷ lệ thiếu vitamin $D$ ở trẻ dưới} 5 tuổi tại Trường Thọ, An Lão năm 2017:

- Tỷ lệ trẻ trai là $54,8 \%$ cao hơn trẻ gái là $45,2 \%$, tỷ lệ trai/gái là 1,2 .

- Lứa tuổi từ 24- 60 tháng chiếm tỷ lệ cao nhất 75,44\%. 
- Tỷ lệ thiếu/hụt Vitamin D ở trẻ là 93,86\%, trong đó trẻ trai là $54,21 \%$ cao hơn trẻ gái là $45,79 \%$

- Tỷ lê trẻ thiếu/hụt Vitamin $D$ cao nhất là ở lứa tuổi từ 24- 60 tháng $(76,17 \%)$.

\section{Triệu chứng lâm sàng của bệnh còi xương ở đối tượng nghiên cứu}

Triệu chứng lẩm sàng:

- 123 trẻ có biểu hiện quây khóc $(53,95 \%)$, trẻ có dấu hiệu ngủ không yên giấc, giật mình là 124 trẻ $(54,39 \%)$, trẻ có dấu hiệu vã mồ hôi, rụng tóc là 124 trẻ $(54,39 \%)$.

- Trong 228 trẻ nghiên cứu của chúng tôi có 214 trẻ có biểu hiện thiếu/hụt Vitamin $D$ tuy nhiên $100 \%$ số trẻ này đều không có các biểu hiện muộn của còi xương thiếu Vitamin $D$ như mềm xương sọ, có bướu trán, biến dạng xương hàm, răng mọc lộn xộn... Chỉ có $14,9 \%$ trẻ có biểu hiện thóp rộng và bờ thóp mềm, có 25 trẻ có biểu hiện chân vòng kiềng chiếm tỷ lệ 10,9\%.

\section{TÀI LIỆ THAM KHẢO}

1. Vũ Thi Thu Hiên và công sư (2012), "Tỷ lê thiếu Vitamin $D$ và một số yếu tố liên quan ở trẻ em 1 đến 6 tháng tuổi tại Hà Nội", Tạp chí Dinh dưỡng và Thực phẩm. 8 (4), tr. 8 - 16.

2. Nguyễn Văn Sơn (2000), Nghiên cứu các yếu tố nguy cơ còi xương dinh dưỡng ở trẻ em dưới 3 tuổi tại một số vùng miền núi phía Bắc và hiệu quả điều trị bẳng vitamin $D$ liều thấp, Luận án tiến sĩ, Trường Đại học Y Hà Nội.

3. Arnaud Laillou et al (2013), "Hypovitaminosis D and Mild Hypocalcaemia Are Highly Prevalent among Young Vietnamese Children and Women and Related to Low Dietary Intake", PLOS ONE. 8(5): e63979. (doi:10.1371/journal.pone.0063979).

4. N. Binkley, R. Ramamurthy và D. Krueger (2012), "Low vitamin D status: definition, prevalence, consequences, and correction", Rheum Dis Clin North Am. 38(1), tr. 45-59.

5. Bener A; Al-Ali M and Hoffmann GF (2009), "Vitamin D deficiency in healthy children in a sunny country: associated factors", Int J Food Sci Nutr. 60 (5): 60-70( doi: 10.1080/09637480802400487).

6. M. Hewison (2012), "Vitamin D and the immune system: new perspectives on an old theme", Rheum Dis Clin North Am. 38(1), tr. 125-39.

7. M. Peterlik và các cộng sự. (2009), "Vitamin $D$ and calcium insufficiency-related chronic diseases: an emerging world-wide public health problem", Int J Environ Res Public Health. 6(10), tr. 2585-607.

8. Jonathan M, Mansbach và Adit A (2009), "Serum 25-Hydroxyvitamin D Levels Among US Children Aged 1 to 11 Years: Do Children Need More Vitamin D", Pediatrics. 124;1404-1410.

9. Strand MA et al (2007), "Diagnosis of rickets and reassessment of prevalence among rural children in northern China", Pediatr Int. 49 (2): 202- 209.

\section{ĐÁNH GIÁ HIÊUU QUẢ ĐÎ̀U TRI BÊNH BẠCH CẦU CẤP DÒNG LYMPHO B Ở TRẺ EM CÓ ĐộT BIẾN CHUYỂN ĐOẠN t(1;19)}

\section{TÓM TẮT}

Mục tiêu nghiên cứu: Đánh giá đặc điểm sinh hoc, hiệu quả điều trị lâu dài, thời gian sống còn và biến chứng điều trị bạch câu cấp lympho B (BCCLB) trẻ em có đột biển $t(1 ; 19)$ bằng phác đồ FRALLE 2000. Phương pháp nghiên cứu: Mô tả hàng loạt ca, hồi cứu. Đối tượng nghiên cứu: 38 bệnh nhẩn (BN) thỏa tiêu chuẩn chọn mẫu với tuổi trung vị là 5 tuổi, được điều trị bằng phác đồ FRALLE 2000 tại khoa Huyết học Trẻ em 1 và Huyết học trẻ em 2 - Bệnh viện Truyền máu Huyết Hơc từ 2010 - 2020. Kết quả: Đột biến sinh học phân tử khác kèm theo là khá phổ biến (39,5\%). Đa số không có kiểu hình miễn dịch bất thường (LAIPs) theo dõi tồn lưu tế bào ác tính (MRD)

\footnotetext{
*Đại Học Y Dược TP. HCM, Bệnh viện Truyền máu Huyêt họ TP. HCM

Chịu trách nhiệm chính: Đinh Gia Khánh

Email: gkhanh94@gmail.com

Ngày nhận bài: 2.6.2021

Ngày phản biện khoa học: 3.8.2021

Ngày duyệt bài: 10.8.2021
}

\section{Đinh Gia Khánh*, Huỳnh Nghĩa*}

(89,5\%). Toàn bộ BN đạt lui bệnh sau giai đoạn tấn công của phác đồ, chúng tôi ghi nhận thời gian sống toàn bộ (OS) và thời gian sống không sự kiện (EFS) sau 5 năm lần lượt là là $84,4 \%$ và $70,9 \%$. Tỉ lệ tái phát tích luỹ là $27,1 \%$. Không có sự khác biệt có ý nghĩa OS, EFS giữa nhóm $\mathrm{t}(1 ; 19)$ đởn độc và nhóm $\mathrm{t}(1 ; 19)$ kèm bất thường khác. MRD dương tính sau tấn công là yếu tố tiên lượng mạnh mẽ nhất, cho EFS khác biệt có ý nghĩa $(p<0,01)$. Biến chứng nổi bật là nhiễm trùng, gặp trong mọi giai đoạn của điều trị. Một trường hợp $(2,6 \%)$ tử vong trong điêuu trị do liệt ruột và sốc nhiếm trùng. Kết luân: MRD dương tính sau tấn công làm tăng nguy cơ tái phát bệnh. Tuy nhiên BCCLB ở trẻ em có $t(1 ; 19)$ đa số không có LAIPs để theo dõi MRD bằng kỹ thuật dòng chảy tế bào (Flow cytometry), công cư sinh học phân tử là trung tâm để theo dõi sau điều trị. Với phác đồ FRALLE 2000 được áp dụng tại bênh viện Truyền máu - Huyết học, hiệu quả điều trị khá tốt, tương đương với điêu trị BCCLB trẻ em nói chung. Cho thây chuyển đoạn $\mathrm{t}(1 ; 19)$ không phải là yếu tố tiên lượng xấu.

Tư khóa: Bach cầu cấp lympho, chuyển đoạn $\mathrm{t}(1 ; 19)$, tổ hợp gen E2A-PBX1 